\title{
Measuring the Efficiency of Health Services Areas in Kingdom of Saudi Arabia Using Data Envelopment Analysis (DEA): A Comparative Study between the Years 2014 and 2006
}

\author{
Sanaa Mohamed Aly Helal \& Haga Abdelrahman Elimam \\ ${ }^{1}$ Faculty of Economics and Administration, University of King Abdul Aziz, Jeddah, Saudi Arabia \\ Correspondence: Sanaa Mohamed Aly Helal, Prof. Dr., Faculty of Economics and Administration, University of \\ King Abdul Aziz, Jeddah, Saudi Arabia. E-mail: sanhelal@yahoo.com
}

Received: February 15, 2017

Accepted: March 18, 2017

Online Published: March 25, 2017

doi:10.5539/ijef.v9n4p172

URL: https://doi.org/10.5539/ijef.v9n4p172

\begin{abstract}
The study aimed to assess the efficiency of health services provided by the government hospitals in various districts of the Kingdom of Saudi Arabia. The number of beds at hospitals, doctors, nursing staff and paramedical categories were used as inputs for the model. The average productivity efficiency of government hospitals in the districts of the Kingdom of Saudi Arabia in 2014 was 92.3\%; whereas, the average internal production efficiency of these districts in the provision of health services through their respective hospitals was $94.7 \%$; and the average external productivity efficiency in the different cities of the districts in Kingdom of the Saudi Arabia was 97.5\%. It has been found that the average overall productivity efficiency was $90.2 \%$, concerning the relative efficiency indicators of government hospitals, which were based on the hospitals' distribution of Saudi Arabian districts in 2006. An analysis of the indicator showed that the average production efficiency of the services provided (internally) by the districts of the Kingdom of Saudi Arabia was $94.7 \%$, and that the average of the external production efficiency for such services was $95.4 \%$. The Data Envelopment Analysis is a successful technique in measuring the performance efficiency of hospitals and it also assists to identify possible improvement and reduction in cost.
\end{abstract}

Keywords: data envelopment analysis (DEA), general efficiency, relative efficiency

\section{Introduction}

\subsection{Problem of the Study}

The Data Envelopment Analysis (DEA) program is considered as one of the constructive programs that contribute to the measurement of the performance efficiency among hospitals. The specification of weaknesses are the areas in the efficiency of using available resources, proposal of optimal allocation of these resources, and increment of efficiency by reducing resources or decreasing outputs (Linna et al., 2006). Therefore, this study aimed to assess the efficiency of health services at Districts of Kingdom of Saudi Arabia, which are provided by the government hospitals (public) in the country. It was divided into 20 districts commencing with Riyadh and ending with Qunfudha (Yearbook, 2014); in addition, to measure the efficiency of the hospitals within each district.

\subsection{Importance of the Problem}

The healthcare services sector in the Kingdom of Saudi Arabia (KSA) has occupied a remarkably distinctive position among the remaining other service sectors. Furthermore, KSA has always been dedicated in considering health services sector as a key objective in all its development plans. However, it has been remarked that it was (and is still) facing challenges, which are represented in the provision of health care for every citizen from one aspect and raising the level of competency of the health care from the other. Therefore, the evaluation of health services and measurement of the hospitals' efficiency have become necessity for ensuring the improvement of services quality and optimum utilization of resources allocated for them. Those in charge of hospital's management confront a number of challenges that are not represented only in the provision of health services, but also in elevating the level of efficiency of these services. It happens because these services are directly linked to the health of individuals and their lives; and that the human resource is the foundation for any real economic and social development. Since human development and economic development are two similar aspects, it could 
be found that the percentage of the development of societies is directly associated to the competency of these health services.

\subsection{Relevant Scholarship}

The concern given by the Saudi government to health services has been underlined by the continuous increase in resources in sums allocated to the Ministry of Health in the country's budget, coupled with parallel increase and the number of hospitals and beds at the Government hospitals, as illustrated in table 1. It indicated the increase in population, budget of the Ministry of Health (MOH) in relation to the country's (Government "Gov.") budget, government hospitals and beds at such hospitals from 2006-2014.

Table 1. Annual reports of the Saudi ministry of health 2006-2014

\begin{tabular}{lcccccc}
\hline Year & $\begin{array}{c}\text { Population } \\
\text { in Millions }\end{array}$ & $\begin{array}{c}\text { No. of } \\
\text { Hospitals }\end{array}$ & No. of Beds & $\begin{array}{c}\text { Government's (Gov.) } \\
\text { Budget in Million SR }\end{array}$ & $\begin{array}{c}\text { MOH 's Budget in } \\
\text { Million SR }\end{array}$ & $\begin{array}{c}\text { \% of MOH's Budget to } \\
\text { Gov's Budget }\end{array}$ \\
\hline 2006 & 23.7 & 120 & 30617 & 335 & 19.7 & 5.9 \\
2007 & 24.2 & 225 & 31420 & 380 & 22.8 & 6.0 \\
2008 & 24.8 & 231 & 31720 & 450 & 25.2 & 5.6 \\
2009 & 25.4 & 244 & 33277 & 475 & 29.5 & 6.2 \\
2010 & 27.0 & 249 & 34370 & 540 & 35.1 & 6.5 \\
2011 & 28.4 & 251 & 34450 & 580 & 39.9 & 6.9 \\
2012 & 29.2 & 259 & 35828 & 690 & 47.1 & 6.8 \\
2013 & 30.0 & 268 & 38970 & 820 & 54.4 & 6.6 \\
2014 & 30.8 & 270 & 40300 & 855 & 60.0 & 7.0 \\
\hline
\end{tabular}

The results of Table 1 showed that in the period between 2006-2014, the positive rate of change in the total number of population reached $30 \%$; and that the positive rate of change in the number of hospitals reached $24 \%$, and the positive rate of change in the number of beds at hospitals reached $32 \%$ and finally the positive rate of change in the budget of the Saudi Ministry of Health reached 204.6\%. Based on the above mentioned information, the following two questions can be represented:

- Do the government hospitals (public) at the Administrative districts in the Kingdom of Saudi Arabia function in the required efficiency?

- What are the procedures that can be adopted so as to address the situation of the Administrative districts that provides health services with low efficiency?

Several studies have focused on measuring the efficiency of health services provided by government hospitals (public) via using DEA; and these studies are considered as the most attractive literature in the management of health services. Furthermore, they do not only prove that DEA is an effective technique for evaluating the efficiency of the organizations providing health care, but they also reflect a group of diversified problems in the management of health care provision that can be effectively handled via DEA. Additionally, a number of these studies have focused on resources and cost; whereas, others have concentrated on the comparison between the technique of DEA and other techniques.

\subsubsection{Expansion of Data Envelopment Analysis Technique (DEA)}

Data Envelopment Analysis technique (DEA) has been expanded in the late seventies of the twentieth century for measuring efficiency in different fields, including education, health, agriculture, industrial, engineering, sports and others. Farrell (1957) is considered the first one, who displayed the basic DEA technique, which was developed later into (CCR Model) in 1957 (Charnes et al., 1957) and then in 1978 (Charnes et al., 1978). This model relied on a scale fixed income, Constant Return Scale (CRS) for measuring the efficiency of Decision-Making Units (DMU). In 1984, Banker developed (CCR) model (Banker, 1984) into (BCC) model by using Variable Return Scale (VRS). However, researchers have employed curve as a measure for efficiency, as any point on this curve determines the amount of inputs or outputs (Niakas \& Kontodimopoulos, 2005).

In the Arab World, DEA is considered as a modern trend in the context of scientific and academic research; and that the first individual who wrote about this matter in Arabic in 1996, was Bahermz (1996), who was followed by Alhdokha and Bahermz in (1997), Azzaz in (2000), Baaikerm in (2002), Al-Shabi in (2004), and Fahmi in (2007). This technique is known as a mathematical method that uses linear programming for measuring relative efficiency of a number of administrative units (decision-making units) through specification of the optimal mixture of a group of its inputs and outputs, based on their actual performance (Joe Zhu, 2003; Cooper, Seiford, 
$\&$ Tone, 2003) and (Bahermz, 1996).

\subsubsection{DEA for Resources of Hospitals}

Evaluating the studies that have given much concern to resources and cost, it has been found that the resources of hospitals have been listed among the significant things in the studies carried out during the recent years. Furthermore, the focus of researchers regarding the efficiency of the hospitals has tremendously increased; either due to the desire for controlling the escalating costs (Bakar et al., 2010) or for achieving the greatest gain in spite of the limited resources (Sorkis \& Talloru, 2002). The study conducted by Iswanto (2015) has focused on the importance of health financing as a necessity for ensuring higher efficiency of health services provided by hospitals in Indonesia. The study has depended on cross-sectional data of the financial statements for the three financial years of (Kimaj) Hospital, during (2011-2013). Furthermore, the cost of goods sold, operational cost, general cost, patient cost and the doctor's fees were considered as variables for the inputs, whereas revenues, gross profit and net profit have been taken as variables for the outputs. The measurement of hospital's performance has been measured by using DEA, which indicated that the efficiency of the hospital was $100 \%$ in 2013 as compared to 2011.

\subsubsection{DEA in Measuring the Efficiency of Hospitals}

The developed and developing countries have relied on measuring the efficiency of the hospital on DEA. Barnum, et al. (2011) used a sample comprising 87 hospitals in Chicago, and compared the development of the techniques for measuring the efficiency of these hospitals in connection for non-replaceable variables (fixed assets), and employed both the modern DEA measurement technique and traditional measuring techniques, such as ratio analysis and regression analysis. The results of the study have indicated that there is exaggeration in the efficiency of certain hospitals when it is measured via traditional measurement techniques. It makes any comparison doubtful between hospitals. Furthermore, the researchers have concluded, in a comparative study between DEA technique and econometric techniques, particularly the non-linear technique (one) using a sample of hospitals in North Carolina State in USA. It has been observed that DEA technique is capable of both specifying the shortcomings and of contributing to the elucidating the percentage of reducing the resources or maximizing the outputs of hospitals. This matter could not be determined by non-linear technique (Banker et al., 1984).

Vincenzo and Rizzi (2006) applied DEA for the measurement of the efficiency of 85 hospitals (public and private) in the city of Veneto, Italy. The researchers found that minimum level of care for achieving the objectives of the hospital administrative policy makers at the hospital led to the reduction of the average of hospital's efficiency. Likewise, the study concluded that public hospitals had low efficiency; that it attributed such reduction to the decision makers of these hospitals and the hospitals' size, and inability of management to control the external factors. The study showed that private hospitals, whether profitable or non-profitable, have efficiency level higher than that of public hospitals. However, the study carried out by Sahin and Bulent (2011), which began the efficiency of hospitals in Turkey during the period between the years (2001-2006), used DEA technique, It has been found that the average efficiency rose up significantly after the Government has applied reformatory policies in the state-owned hospitals; whereas, the average of efficiency decreased in the same period in the private hospitals, particularly after due launching of reforms at the state-owned hospitals.

\subsubsection{DEA in the Field of Healthcare}

DEA technique has been warmly received by researchers and practitioners at the hospitals of both public and private sectors. But, despite of the above, DEA has not been employed widely in the field of health care. David Sherman (1984) was the first researcher, who applied DEA at the group of teaching hospitals, and presented the aspects of shortcomings at hospitals. The study conducted by Al-Shayea (2011) was based on the measurement of the performance and efficiency of the departments at King Khalid University Hospital during the 12-month period. The results showed that only two of the nine department's efficiency reached $100 \%$ during the period. In the same year, another study was published in Britain and included the usage of DEA technique in measuring the efficiency of public polyclinics in three English districts (Szczequra et al., 1993).

Another study forecasted the non-governmental hospitals in USA with poor performance. Results indicated that efficiency was a positive sign, but it was weak in predicting the necessity of the hospital's closure (Lynch \& Ozcan, 1994). A study emphasized that DEA is considered as a constructive technology for the managers of health care to achieve an improvement in the efficiency of hospitals' performance (Nayar \& Ozcan, 2008).

A similar study applied DEA technique to nine hospitals providing obstetric services. The study stressed the importance of this technique in measuring the efficiency and effectiveness. This justifies its inclusion among the 
group of tools used by cost managers at Hospitals (Finkler \& Wirtschafter, 1993). The study conducted by Hussein (2011) highlighted the significance of health services in general and hospitals, particularly as one of the most important indicators for social and technological advancement of people. To augment these activities, decision-makers need to know the results of their decisions and performance efficiency is considered as one of the most important decisions.

The inputs of health-system are expected to yield a definite output, which usually refer to the labor and financial quantities and related capacities, whereas the inputs concerning the non-health inputs are referred by the income and reference to education levels (Kim \& Kang, 2014). It has been noted by Greene (2004) that health expenditure is the primary and most dominant factor of input for the productivity evaluation of healthcare management programs. Labor related inputs have been incorporated by some studies in the DEA formulation by using international dataset (Afonso \& St Aubyn, 2005; Bhat, 2005; Retzlaff-Roberts et al., 2004). It is because the addition of labor related inputs may indicate the parsimonious DEA model at an organizational level.

The aim of the study conducted by Laura et al. (2014) was to assess the efficiency of public health care systems in Europe, through the application of DEA technique, which is considered a non-teaching one. When DEA was applied to 30 European countries in 2010, the variables of inputs of the technique comprised a number of doctors, number of beds at hospitals and public health expenditure as a percentage of GDP; whereas, the variables of outputs included possibilities of a new born staying alive at delivery, life expectancy and infant mortality rate. The results concluded that there are a number of developed and developing countries that lie on the limits of efficiency; whereas, the vast majority of countries in the sample are incompetent. Despite the fact that many studies have underlined the importance of DEA in measuring efficiency, it has been found that many researchers are of the opinion that DEA is not a useful technique for evaluating efficiency, without the presence of additional sources (Szczepura et al., 1993).

\subsection{Contribution of the Study}

The data envelopment analysis has been suggested by the study to manage the efficiency of the hospital management and services according to the nature of activities performed by the hospitals. The differences and diversity between several activities within the hospital can also be managed by the DEA technique. The study has contributed to measure the efficiency of the hospitals for the years 2006-2014 using the DEA technique. The study demonstrated that efficiency of the hospitals can be easily analyzed with tools and indicators developed by the econometrician, stakeholders and statisticians to measure the efficiency and human productivity. DEA is efficient enough to manage the input and output ratios, which do not comprise of all inputs and outputs.

\section{Method}

The population included 270 public hospitals of the Ministry of Health, Kingdom of Saudi Arabia, distributed over 20 Administrative districts, in the year 1435/2014. This number was compared with 220 hospitals, distributed over the same number of Administrative districts for the year 1426/2006. Annual Health Statistical book issued by the Ministry of Health in the Kingdom of Saudi Arabia in 2006-2014 was considered as one of the data collection methods. The selection of the inputs and outputs is considered as one of the important factors in assessing the efficiency of hospital via using DEA technique, because it directly impact the results that were obtained. The study employed these variables (Yearbook of the Ministry of Health 2014-2006) and inputs for all public (government) hospitals at each Administrative District in the Kingdom of Saudi Arabia) consisted the number of beds, number of doctors, number of nurses, and number of personnel of allied medical (health) categories. Outputs for all public (government) hospitals at each Administrative District in the Kingdom of Saudi Arabia comprised the number of individuals visiting admitted patients. The number of inpatients, number of beneficiaries from the radiography service, and number of beneficiaries from laboratory tests have also been included.

\subsection{The Most Important Models of the Technique of Data Envelopment Analysis (DEA)}

Models of the Technique of Data Envelopment Analysis (DEA) can be classified into four basic models that include CRS Model (Constant Return Scale) or CCR Model, (logarithmic) Multiplicative Model, Additive Model and BCC Variable Return Model, (Bahermz, 1996; Fahmi, 2006; Babakor, 2002). The researcher has used BCC Model and CCR Model, technical efficiency (overall efficiency), assuming constant return in relation to production (CRS). Charles, Cooper and Rhodes (Charnes et al., 1978) evolved this model, which was considered as the main model of all the above mentioned ones (Data Envelopment Analysis). Through this particular model, relative efficiency of administrative units under analysis has been evaluated; and that the sources and amount of inefficiency for each administrative unit have been determined. The relative efficiency of any unit (jo) has also been calculated for other units. It is worthy to mention, that CCR model is a model with constant return to 
production model Constant Return to Scale (CRS), denoting that the rate of return on production increases at the same rate of increase in the factors of production. This property, which is known as the constant return to production, is considered appropriate only when all units subjected to comparison operating at the level of their optimal sizes (overall efficiency). But, in fact there may be a lot of obstacles that prevent the units from achieving these sizes, such as incomplete competition, funding constraints and others. CCR Model takes following formula:

$$
\begin{array}{ll}
\operatorname{Min} \theta & \text { S.C } \\
\sum_{j=1}^{n} \lambda_{j} x_{i j} \leq \theta x_{i j 0} & i=1,2, \ldots \ldots m ; \\
\sum_{j=1}^{n} \lambda_{j} y_{r j} \geq y_{r j o} & r=1,2, \ldots \ldots \ldots s \\
\lambda_{j} \geq 0 & j=1,2, \ldots \ldots \ldots n ;
\end{array}
$$

where: n: number of administrative units, m: number of inputs, $s$ : Number of outputs, jo: unity whose efficiency is required to be measured, $\theta$ the degree of efficiency $(0 \leq \theta \leq 1): \lambda_{j}$ : weight of the unit xij: the amount of input $\mathrm{i}$ for unit $\mathrm{j}$, yij: amount of input $\mathrm{r}$ for unit $\mathrm{j}$ entrance of the unit $\mathrm{i} j, \mathrm{r}$ the amount of the entrance of the unit $\mathrm{j}$.

$x_{i j o}$ : amount of input $\mathrm{i}$ for unit whose efficiency is required to be measured jo, yij of amount of input $\mathrm{r}$ for unit whose efficiency is required to be measured jo. Also, the values of the units under study are fixed values obtained from the past information related to the inputs and outputs resulting then, as it must be noted that the best values of the weights may change from one unit to another (Lewin et al., 1981).

\subsection{BCC Model (Banker-Charnes-Cooper) Variable Return Model}

This particular Model was developed to overcome the disadvantages of CCR Model as presented by Charles et al. (1984). The assumption adopted by that CCR Model that returns on production was constant and does no longer apply to certain productivity unit. However, BCC model, which was amended from DEA Model, assumes that return on production was not constant. Furthermore, Charnes (1994) distinguished in this Model between technical efficiency and size efficiency (one) through the following points:

- Determine the technical efficiency at in a certain level of operations.

- Specify the possibility for availability of constant increasing or decreasing return on production.

This means that this model plays a role of regressor in the model, on the volume of production (Variable Return Scale) (Joe Zhu, 2003). The following mathematical formula in the event represented the goal to reduce the amount of input Orientation (Cooper et al., 2007).

$$
\begin{aligned}
& \operatorname{Min} \theta \\
& \sum_{j=1}^{n} \lambda_{j} x_{i j} \leq \theta x_{i j o} \\
& \text { S.C } \\
& \sum_{j=1}^{n} \lambda_{j} y_{r j} \geq y_{\text {rjo }} \\
& i=1,2, \ldots s m_{*}^{x} \\
& \sum_{j=1}^{n} \lambda_{j}=1 \quad \lambda_{j} \geq 0 \\
& r=1,2 \ldots \ldots s s_{*}^{x} \\
& j=1,2 \ldots \ldots n_{p}
\end{aligned}
$$

\section{Results}

It is worth mentioning that (DEA) model measures efficiency, depending on the size of existing operations in DMU to provide services to the beneficiaries during the period of measurement. Furthermore, this model secures the possibility of the presence of constant increase or decrease in returns on the scope of effective units, which resulted from the change in the quantity of inputs to obtain efficiency (Cooper et al., 2003).

Sherman and Joe (2006) classified DEA technique as the best way for reference comparison (Benchmark), due to the excellence in specifying the best counterpart units, depending on many inputs and outputs. Furthermore, the efficiency measurement with this technique does not require provision of information on the prices of inputs or outputs; and it is not stipulated that the inputs and outputs should be of the same measurement unit, but concentration should be made on decision making units. Additionally, there is no restriction in using a particular form of production functions that meet the strict justice criteria for each unit decision-making unit (Manzoni, 2009).

BCC model was used among other Models or techniques of DEA for measuring hospitals' efficiency. The researcher has employed this model, because it gives a variable return on the volume of production and that it is possible to know whether the return is constant, increasing or decreasing. Furthermore, reduction of inputs and increment of outputs have been dully chosen (Charnes, 1985; Bahermz, 1994). DEA was applied to the data of the hospitals (public) of the Ministry of Health, which are distributed over 20 Administrative Districts of the Kingdom of Saudi Arabia to measure efficiency at these hospitals. The results are indicated in the Table 2: 
Table 2. Comparison between the efficiency of health services provided by hospitals at the administrative districts of the Kingdom of Saudi Arabia between the years 2006-2014

\begin{tabular}{|c|c|c|c|c|c|c|c|c|c|}
\hline \multirow{3}{*}{$\begin{array}{l}\text { Administrative } \\
\text { Districts }\end{array}$} & \multicolumn{4}{|c|}{ Efficiency Indicator for the year 2014} & \multicolumn{5}{|c|}{ Efficiency Indicator for the year 2006} \\
\hline & $\begin{array}{c}\text { General } \\
\text { Operation } \\
\text { Efficiency } \\
\text { CRS(\%) }\end{array}$ & $\begin{array}{c}\text { Internal } \\
\text { Operation } \\
\text { Efficiency } \\
\text { VRS(\%) }\end{array}$ & $\begin{array}{l}\text { External } \\
\text { Operation } \\
\text { Efficiency } \\
\text { Scale }(\%) \\
\end{array}$ & $\begin{array}{c}\text { Causes } \\
\text { of } \\
\text { inefficiency }\end{array}$ & $\begin{array}{c}\text { Administrative } \\
\text { Districts }\end{array}$ & $\begin{array}{c}\text { General } \\
\text { Operation } \\
\text { Efficiency } \\
\text { CRS(\%) }\end{array}$ & $\begin{array}{c}\text { Internal } \\
\text { Operation } \\
\text { Efficiency } \\
\text { VRS(\%) }\end{array}$ & $\begin{array}{l}\text { External } \\
\text { Operation } \\
\text { Efficiency } \\
\text { Scale(\%) }\end{array}$ & $\begin{array}{c}\text { Causes } \\
\text { of } \\
\text { inefficiency }\end{array}$ \\
\hline & GE & IE & $\mathrm{EE}$ & & & GE & IE & $\mathrm{EE}$ & \\
\hline Medinah & 100 & 100 & 100 & --- & Medinah & 100 & 100 & 100 & --- \\
\hline Qaseem & 100 & 100 & 100 & --- & Qaseem & 100 & 100 & 100 & --- \\
\hline Eastern & 100 & 100 & 100 & --- & Hafr Al-Baten & 100 & 100 & 100 & --- \\
\hline Al-Ahsa & 100 & 100 & 100 & --- & Aseer & 100 & 100 & 100 & -- \\
\hline Bishah & 100 & 100 & 100 & --- & Bishah & 100 & 100 & 100 & --- \\
\hline Jazan & 100 & 100 & 100 & --- & Ha'il & 100 & 100 & 100 & --- \\
\hline Al-Bahah & 100 & 100 & 100 & --- & Northern & 100 & 100 & 100 & --- \\
\hline Qurayyat & 100 & 100 & 100 & --- & Najran & 100 & 100 & 100 & --- \\
\hline Qunfudah & 100 & 100 & 100 & --- & Al-Bahah & 100 & 100 & 100 & --- \\
\hline Tabouk & 97.9 & 98.3 & 99.6 & $\mathrm{IE}, \mathrm{EE}$ & Qunfudah & 100 & 100 & 100 & \\
\hline Aseer & 97.5 & 100 & 97.5 & $\mathrm{EE}$ & Qurayyat & 96.6 & 100 & 96.6 & $\mathrm{EE}$ \\
\hline Makkah & 96.7 & 100 & 96.7 & $\mathrm{EE}$ & Al-Ahsa & 95.5 & 97.7 & 97.7 & $\mathrm{IE}, \mathrm{EE}$ \\
\hline Ta'if & 91.5 & 100 & 91.5 & $\mathrm{EE}$ & Eastern & 92.5 & 100 & 92.5 & $\mathrm{EE}$ \\
\hline Ha'il & 87.4 & 98.2 & 88.9 & IE, EE & Jazan & 90.2 & 100 & 90.2 & $\mathrm{EE}$ \\
\hline Riyadh & 85.9 & 100 & 85.9 & $\mathrm{EE}$ & Tabouk & 84.8 & 95.4 & 88.9 & $\mathrm{IE}, \mathrm{EE}$ \\
\hline Northern & 83.8 & 92.4 & 90.8 & IE, EE & Makkah & 78.8 & 100 & 78.8 & $\mathrm{EE}$ \\
\hline Hafr Al-Baten & 80.5 & 80.6 & 99.9 & $\mathrm{IE}, \mathrm{EE}$ & Al-Jouf & 71.8 & 74.2 & 96.7 & $\mathrm{IE}, \mathrm{EE}$ \\
\hline Najran & 78.4 & 78.8 & 99.6 & IE, EE & Riyadh & 70 & 100 & 70 & $\mathrm{EE}$ \\
\hline Jeddah & 74.8 & 75.2 & 99.4 & IE, EE & Ta'if & 67.9 & 69.4 & 97.8 & $\mathrm{IE}, \mathrm{EE}$ \\
\hline Al-Jouf & 70.9 & 71 & 99.9 & IE, EE & Jeddah & 56.6 & 57.6 & 98.4 & IE, EE \\
\hline Average & 92.3 & 94.7 & 97.5 & IE, EE & Average & 90.2 & 94.7 & 95.4 & IE, EE \\
\hline
\end{tabular}

From Table 2, the most important findings have been extracted that are reached through the application of Data Envelopment Analysis to government hospitals in the Administrative Districts of the Kingdom of Saudi Arabia for the year 2014. The table shows the general efficiency of the selected Administrative Districts that provide health services via government hospitals. The general efficiency, in turn, is divided into internal efficiency and external efficiency (Abou El- Seoud, 2013; Nadir et al., 2013).

\subsection{General Efficiency}

It denotes the level of efficiency of the administrative unit (of hospitals) in the utilization of available resources (inputs) and its ability to overcome external factors to secure the provision of the best possible service to the beneficiaries (outputs). If the general efficiency is $100 \%$, this means that the relative efficiency has become complete.

\subsection{Internal Efficiency}

It denotes the exploitation of the hospital's management for the available resources (inputs) for the provision of the best possible health services to the beneficiaries (outputs).

\subsection{External Efficiency}

It signifies the efficiency of the hospital's management in overcoming the external factors, which negatively affect the level of service provided by them to (outputs).

By analyzing the results of the table's relative efficiency of the hospitals in the Administrative Districts, there were many remarked points. The average of the general productive efficiency throughout the Administrative Districts of the Kingdom of Saudi Arabia in general is (92.3\%). This means that the government hospitals in the selected districts must be able to provide the same level of output (number of individuals visiting inpatients, the number of laboratory tests, number of beneficiaries benefiting from radiography service) or more (if their objective is to reduce inputs together with maintaining the same level of outputs). However, with the usage of only $(92.3 \%$ ) or less of the current inputs (the number of doctors, the number of nurses, the number of allied 
health personnel), the selected hospital has been efficient. In other words, they must reduce the inputs with a percentage of $(7.7 \%)$ together with maintaining the current amount of outputs to show that they were efficient. But if the goal of the hospitals is to maximize outputs while maintaining the same amount of inputs, this means that government hospitals across the Administrative Districts of the Kingdom of Saudi Arabia must increase services by $(8.3 \%)$, to reach the complete general efficiency. This represents the inverse of the efficiency indicator in this case (Al-Ahmadi, 2009).

When the selected indicator has broken down, it become conspicuous that the average of internal operation efficiency (IE) for the government's hospitals across the Administrative Districts of the Kingdom of Saudi Arabia is generally (94.7\%). The average of EE (External Operation efficiency (EE) of the government hospitals across the Administrative Districts of the Kingdom of Saudi Arabia is generally (97.5\%). This means that, the inability of the government's hospitals to reach the complete general efficiency across the Administrative Districts of the Kingdom of Saudi Arabia, is basically due to the weakness of the efficiency level for managing internal operations more than weakness of the efficiency level for managing and overcoming of the external environmental factors.

The number of hospitals, that attribute inefficiency to the weakness management level in the general overcoming of the external environmental factors and the weakness of the level of efficiency in managing internal operations, was eleven. Whereas, it has been found that only seven hospitals attribute inefficiency to the general weakness of the level of efficiency in managing internal operations.

\subsection{Relative Efficiency Indicators of Government'S Hospitals in 2006}

The average of the General productive efficiency (GE) throughout the Administrative districts of the Kingdom of Saudi Arabia in general is $(90.2 \%)$. This means that the government hospitals in the selected districts must be able to provide the same level of output (number of individuals visiting inpatients, the number of laboratory tests, number of beneficiaries benefiting from radiography service) or more (if their objective is to reduce inputs together with maintaining the same level of outputs). However, with the usage of only (90.2\%) or less of the current inputs (the number of doctors, the number of nurses, the number of allied health personnel), the selected hospital could be efficient. In other words, they must reduce the inputs with a percentage of $(9.2 \%)$ together with maintaining the current amount of outputs so that they were being efficient. But if the goal of the hospitals is to maximize outputs while maintaining the same amount of inputs, this means that government hospitals across the Administrative Districts of the Kingdom of Saudi Arabia must increase the services by (8.3\%) and increase their services by $(10.9 \%)$ to reach the complete general efficiency. This represents the inverse of the efficiency indicator in this case (Talal, 2009).

When the selected indicator broken down, it become obvious that the average of internal operation efficiency (IE) for the government's hospitals across the Administrative Districts of the Kingdom of Saudi Arabia is generally (94.7\%), and the average of External productive efficiency (EE) of the government hospitals across the Administrative Districts of the Kingdom of Saudi Arabia is generally (95.54\%). This means that the inability of the government's hospitals reach the complete general efficiency across the Administrative Districts of the Kingdom of Saudi Arabia. It is evident from the above table that the groups of government hospitals at the Administrative Districts that failed to achieve the relative efficiency can be divided into two categories:

- The government hospitals, that attribute their failure to achieve relative efficiency to the weakness of their management in overcoming the environmental or external factors as well as to the weaknesses in the internal management processes, and these hospitals are located in Tabuk, Hail, Riyadh, the northern border, Hafr Al-Batin, Najran, Jeddah, Al-Jawf.

- The group of government hospitals, that attribute their failure to achieve relative efficiency to the weakness of their management in overcoming the environmental or external factors, and these hospitals are located in: Asir, Makkah, Taif, and Riyadh.

\subsection{The Options Available to Inefficient Hospitals for Improving Their Efficiency}

There are many useful information provided by Data Envelopment Analysis. In addition to determining inefficient units (those who failed to achieve complete general relative efficiency), this analysis technique determines the amount of inefficiency at inefficient units and the proposed amounts for each of them to become efficient. Whether the goal is to maximize the outputs (output maximization) or to reduce the inputs (input minimization); in order to improve efficiency so that incompetent hospitals become really competent. The column labeled "actual values" indicates the value of used inputs and the values of produced output, which was actually produced at inefficient hospital in Jeddah Province. However, the column labeled (targeted) values 
indicates the target and the values of the amounts of inputs and outputs that should be produced by inefficient hospitals. This study has applied the options available for improving the efficiency of inefficient government hospitals at Jeddah Province so that they are become efficient.

\subsection{The Options Available to Inefficient Hospitals in Jeddah Province for Improving Their Efficiency}

First Option: Reduction in inputs and obtaining the same outputs: Through the application of DEA with the usage of input minimization, the results in the following Table 3 are as follows:

Table 3. Level of reduction in inputs and obtaining the same outputs at inefficient hospital in Jeddah Province

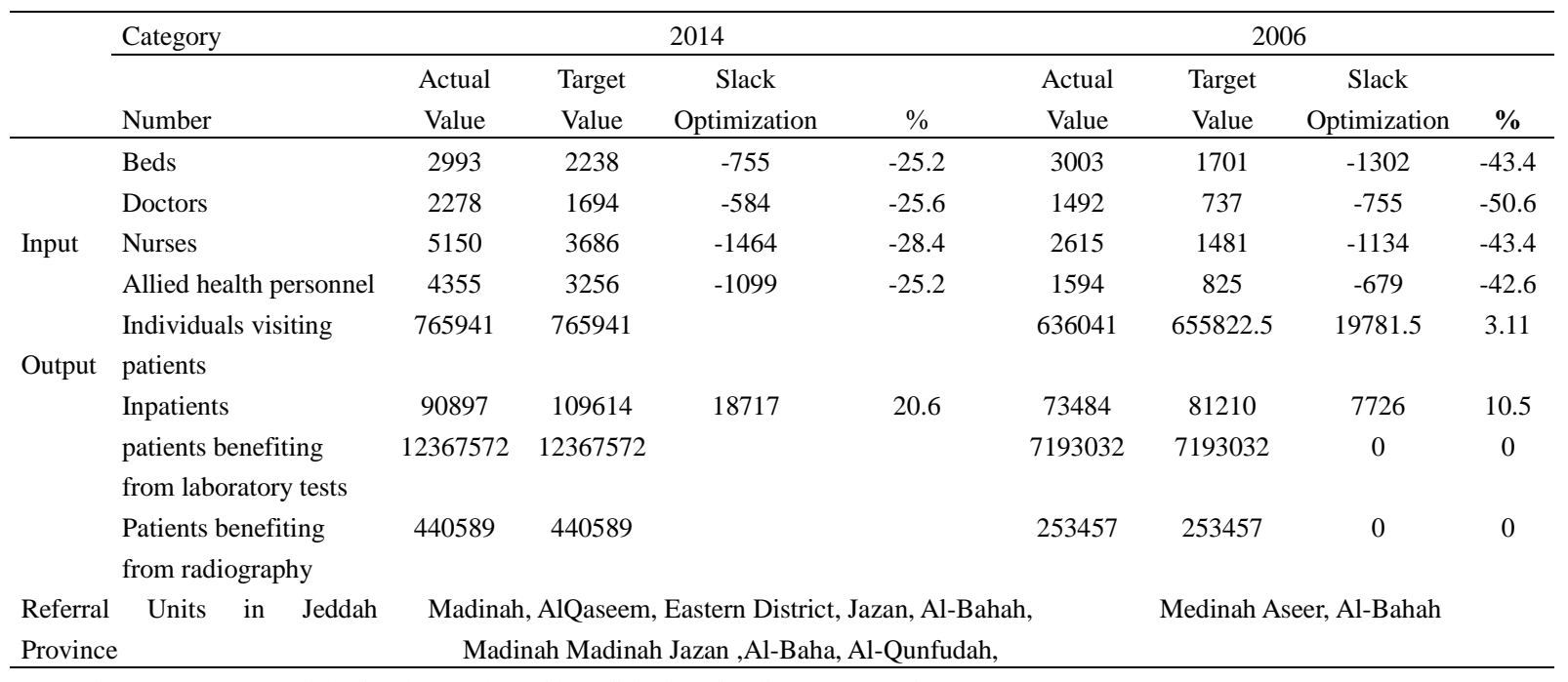

Out-Patients Department Visits for the number of beneficiaries of radiography service.

From the results of the above table 3, following conclusion can be made:

- In order to reach the complete efficiency, like their referral hospitals, government hospitals in the Province of Jeddah region in 2014 should reduce the number of beds to 755 or by $(25.2 \%)$ and reduce the number of doctors to 584 , i.e. $(25.6 \%)$, and reduce the number of nurses to 1464 i.e. $(28.4 \%)$, and reduce the number of allied health personnel 1099 i.e. (25.2\%). However, there is room for increasing the number of inpatients to 18,717 patients i.e. $(20.6 \%)$ after this reduction in inputs.

- Likewise, the same option at all inefficient government hospitals can be applied in other Provinces, and which were indicated in table 2; and the desired improvement referral units can be achieved as applied in inefficient government hospitals at Jeddah Province

- When the efficiency in the performance of government hospitals for 2014 and 2006 was compared, its aspects can be summarized via the results of the selected table through the usage of DEA in the following points:

- There was reduction in the number of beds at hospitals for 2014 compared to 2006 with a percentage of $18.2 \%$.

- There was reduction in the number of doctors in 2014 compared with 2006 with a percentage of $25.0 \%$.

- There was reduction in the number of nurses in 2014 compared with 2006, with a percentage of $15.0 \%$.

- There was reduction in the number of allied health personnel in 2014 compared with 2006, with a percentage of $17.4 \%$.

- There was increase of the number of inpatients in 2014 compared with 2006 with a percentage of $10.6 \%$ after this reduction in inputs.

\subsection{Second Option: An Increase in Outputs at the Same Inputs}

The following table 4 shows the increases that must be obtained as the outputs at the same number of inputs, through the application of DEA with the use of outputs output maximization: 
Table 4. Levels of required increases in the outputs at the same inputs for inefficient hospitals in Jeddah Province

\begin{tabular}{|c|c|c|c|c|c|c|c|c|c|}
\hline & \multirow{2}{*}{$\frac{\text { Category }}{\text { Number of }}$} & \multicolumn{4}{|c|}{2014} & \multicolumn{4}{|c|}{2006} \\
\hline & & $\begin{array}{l}\text { Actual } \\
\text { Value }\end{array}$ & $\begin{array}{l}\text { Target } \\
\text { Value }\end{array}$ & $\begin{array}{c}\text { Slack } \\
\text { Optimization }\end{array}$ & $\%$ & $\begin{array}{l}\text { Actual } \\
\text { Value }\end{array}$ & $\begin{array}{l}\text { Target } \\
\text { Value }\end{array}$ & $\begin{array}{c}\text { Slack } \\
\text { Optimization }\end{array}$ & $\%$ \\
\hline & Beds & 2993 & 2238 & 0 & 0 & 3003 & 0 & 0 & 0 \\
\hline & Doctors & 2278 & 2266 & -12 & 0 & 1492 & 1301 & -191 & 13 \\
\hline \multirow[t]{3}{*}{ Input } & Nurses & 5150 & 4930 & -220 & 0 & 2615 & 2615 & 0 & 0 \\
\hline & Allied health personnel & 4355 & 4355 & 0 & 0 & 1594 & 1457.2 & -137 & 8.6 \\
\hline & individuals visiting & 765941 & 1024415 & 258474 & 34 & 636041 & 1157984 & 521943 & 82 \\
\hline \multirow[t]{4}{*}{ Output } & inpatients & & & & & & & & \\
\hline & Inpatients & 90897 & 146604 & 55707 & 61 & 73484 & 143392 & 56266 & 95 \\
\hline & $\begin{array}{l}\text { patients benefiting } \\
\text { from laboratory tests }\end{array}$ & 12367572 & 16541127 & 4173555 & 34 & 7193032 & 12700712 & 5507680 & 77 \\
\hline & $\begin{array}{l}\text { patients benefiting } \\
\text { from radiography }\end{array}$ & 440589 & 589270 & 148681 & 34 & 253457 & 447528 & 194071 & 77 \\
\hline $\begin{array}{l}\text { Referral } \\
\text { Province }\end{array}$ & Units in Jeddah & \multicolumn{4}{|c|}{$\begin{array}{l}\text { Madinah, AlQaseem, Eastern District, Jazan, Al-Bahah, } \\
\text { Madinah Madinah Jazan, Al-Baha, Al-Qunfudah, }\end{array}$} & \multicolumn{3}{|c|}{ Medinah, Aseer, Al-Bahah } & \\
\hline
\end{tabular}

When the results of the Table 4 were summarized on the health services provided by the hospitals in Jeddah Province, it has been found that the selected table illustrates how to reach the current inputs with the complete efficiency, like referral hospitals. The government hospitals in the city of Jeddah should increase the reception of patients at different clinics at such hospitals with a percentage of (34\%), increase the number of inpatients by (61\%); and that they increase the number of patients benefiting from radiography service by (34\%), and increase the number of laboratory tests at their respective primary health care centers by (34\%). After these increases in outputs, it can also reduce the number of doctors to 12 with a percentage of $(0.5 \%)$ and finally reduce the number of allied health personnel working at respective primary health care centers to (220) i.e. at a percentage of $4 \%$.

- Similarly, the same option to all inefficient government hospitals can be applied in other Administrative Districts; and that reach the desired level of improvement and referral units as applied in inefficient government hospitals at Jeddah Province.

- When the efficiency in the performance of government (public) hospitals in 2014 with that in 2006 is compared, this can be summed up through the results of the table via using the DEA program (technique) in the following points:

- There was an improvement in the number of individuals visiting clinics in 2014 compared with that in 2006 by $48 \%$.

- There was an improvement in the number of patients in 2014 compared with that in 2006 by $34 \%$.

- There was an improvement in the number of those benefited from the laboratory tests in 2014 compared with that in 2006 by $43 \%$.

- There was an improvement in the number of those benefited from radiography service in 2014 compared with that in 2006 by $43 \%$.

\section{Discussion}

The average general productivity efficiency of government hospitals across the Administrative Districts of the Kingdom of Saudi Arabia in 2014, was generally 92.3\% in comparison with that of $90.2 \%$ for the same hospitals in 2006. The groups of government hospitals at the Administrative Districts that failed to achieve the relative efficiency can be divided into two categories:

- The government hospitals, that attribute their failure to achieve relative efficiency to the weakness of their management in overcoming the environmental are located in Tabuk, Hail, Riyadh, the northern border, Hafr Al-Batin, Najran, Jeddah, Al-Jawf.

- The group of government hospitals that attribute their failure to achieve relative efficiency to the weakness of their management in overcoming the environmental or external factors, and these hospitals are located in: Asir, Makkah, Taif, and Riyadh.

The referral for the general hospitals of Jeddah Province in 2014 included those located at the Provinces of 
Medina, Jizan, Al-Baha and Qunfudah 2014. Whereas, referral hospitals for the same Jeddah's general hospitals in 2006 comprised those situated in the Provinces of Medina, Asir and Baha. The average general productive efficiency for government hospitals of Jeddah Province was $74.8 \%$ in 2014, compared with that of 56.6\% in 2006 for the same hospitals. Furthermore, it turns out that the average internal productive efficiency of government hospitals of Jeddah Province was (75.2\%) in 2014 compared with 57.6\% in 2006 for the same hospitals. Likewise, average of external productive efficiency for government of Jeddah Province was $99.4 \%$ in 2014, compared with that of (98.4\%) in 2006 for the same hospitals. This means that the inability of the government hospitals to reach the complete general efficiency across the Administrative Districts of the Kingdom of Saudi Arabia, was basically due to the weakness of the efficiency level for managing internal operations more than weakness of the efficiency level for managing for the general overcoming of the external environmental factors.

The study indicated that there are two options for inefficient hospitals at Jeddah Province to reach efficiency; the first option is via reductions in inputs and obtaining of outputs and second option is via increasing outputs at the same levels of outputs. With application of these two options. The comparison of the performance efficiency of inefficient government (public) hospitals via reduction of resources (inputs) and obtaining of the same services (outputs) in 2014 from 2006 can be summarized. There was a reduction in the number of beds by $18.2 \%$, and a reduction in the number of doctors by $25 \%$, as the reduction in the number of nurses by $15 \%$, reduction in allied health service personnel by $17.4 \%$ and finally an increase in the number of inpatients in 2014 from 2006 by $10.1 \%$ after this reduction in inputs. The comparison of the performance efficiency of inefficient government (public) hospitals in 2014 from 2006 can be summarized. There was a remarkable improvement in the number of individuals visiting patients by $48 \%$ for the improvement in the number of inpatients by $34 \%$. In addition to the previously mentioned improvement in the number of those benefited from laboratory tests by $43 \%$, and finally an improvement in the number of those benefiting from radiography service improved by $43 \%$.

Regardless of the knowledge about the effectiveness in healthcare delivery, the healthcare performance conceptualization has remained imperfect. There is inefficient healthcare system, which is often determined by the unsatisfactory and inadequate measures of uncertain objectives and misidentified service activities (Kim \& Kang, 2014). Successive studies have proclaimed that the processes of health care delivery appear to be less vigorous and less routinized as compared to other areas and it remains highly sensitive in terms of different environmental settings (Spinks \& Hollingsworth, 2009; Hollingsworth, 2008). DEA allows the productivity assessments of every country and its healthcare system through comparing a relatively technical efficiency to its peer group.

The DEA technique has certain drawbacks, it produces outcomes that are specifically sensitive to the error measurements. If an organization or hospital can become an outlier that more prominently distorts the frontier shape and reduces the effectiveness of scores nearby organizations or other hospitals. DEA has another drawback that it only evaluates the efficiency relative to the particular sample of best practices (Cooper et al., 2006).

This study presented that Data Envelopment Analysis (DEA) technique (Model, which is successful in measuring performance efficiency of hospitals. Moreover, DEA allows analysis of various aspects of shortcomings and helps to identify possible improvements and specify the possible reduction in cost. Relative Efficiency Scale is considered a good indicator for evaluation and comparison of the performance of government hospitals in Administrative Districts of the Kingdom of Saudi Arabia. By using the technique DEA for measuring the degree of efficiency and specification of causes of inefficiency, their sources and, as well as by applying the selected technique to 20 Administrative Districts in the framework of comparison of hospitals performance between 2014 and 2006, The following results have been obtained:

\subsection{Recommendations}

Based on the results, the study presents some recommendations as follows:

- Encourage the studies for the determination of the causes that for the lack of government hospitals from achieving relative efficiency with a view to secure optimal utilization of available resources, via comparing the levels (inputs/outputs) of these hospital with the levels (inputs/outputs) of the referral hospitals.

- Urge to carry out periodical (annually or biennially) studies on performance measurement at the level of primary health care centers and government hospitals regular studies (annual or biennial). It must highlight the comparative performance between public hospitals in 2014 and in 2006 so as to ensure of the good utilization of their resources and that they enjoy high efficiency.

- Provide detailed information to researchers about the resources and outputs of hospitals to conduct such an 
important study.

- Direct to conduct a study on measuring the impact of external factors on efficiency rates, which include the impact of the hospital's site (densely populated/thinly populated area), the nature of the city where the hospital is located, the demographic composition of the city, the proportion of residents in the city to the citizens etc.

- Request to redistribute health resources, the most significant of which is manpower, at government hospitals with low productivity over hospitals and primary health care centers with high productive efficiency.

\section{Acknowledgments}

The authors are very thankful to all the associated personnel in any reference that contributed in/for the purpose of this research. Further, this research holds no conflict of interest and is not funded through any source.

\section{References}

AbouEl-Seoud, M. (2013). Measuring efficiency of reformed public hospitals in Saudi Arabia: An application of data envelopment analysis. Int J Econ Manag Sci, 2(9), 44-53.

Afonso, A., \& St Aubyn, M. (2005). Non-parametric approaches to education and health efficiency in OECD countries. Journal of Applied Economics, 8(2), 227. https://doi.org/10.2139/ssrn.498383

Al-Azzaz, A. B. S. (2000). The Use of Data in the Performance Management. Accounting Research Magazine, $4(1)$.

Al-Shayea, A. M. (2011). Measuring hospital's units' efficiency: A data envelopment analysis approach. International Journal of Engineering \& Technology, 11(6), 7-19.

Alshdokhai, H. N. B., \& Asma, M. (1997). The study of the efficiency of banks by Using Data Envelopment Analysis: A Case Study of Applied Study for a Saudi bank. Business Research Journal, 207-239.

Bahermz, A. M. (1996). Data Envelopment Analysis - the Usage of linear Programming in Measuring the Relative Efficiency of Administrative Units. Public Administration, 36, 317-346.

Banker, R. D., Charnes, A., \& Cooper, W. W. (1984). Some models for estimating technical and scale inefficiencies in data envelopment analysis. Management Science, 30(9), 1078-1092. http://dx.doi.org/10.1287/mnsc.30.9.1078

Barnum, D. T., Walton, S. M., Shields, K. L., \& Schumock, G. T. (2011). Measuring hospital efficiency with data envelopment analysis: Nonsubstitutable vs. Substitutable inputs and outputs. Journal of Medical Systems, 35(6), 1393-1401. https://doi.org/10.1007/s10916-009-9416-0

Bhat, V. N. (2005). Institutional arrangements and efficiency of health care delivery systems. The European Journal of Health Economics, 6(3), 215-222. https://doi.org/10.1007/s10198-005-0294-1

Charnes, A., Cooper, W. W., \& Rhodes, E. (1978). Measuring the efficiency of decision making units. European Journal of Operational Research, 2(6), 429-444. https://doi.org/10.1016/0377-2217(78)90138-8

Charnes, A., Cooper, W., Lewin, A., \& seiford, L. (1994). Data Envelopment Analysis- theory, Methodology and Applications. Boston: Kluwer Academic Publishers. https://doi.org/10.1007/978-94-011-0637-5

Cooper W. W., Seiford, L. M., \& Kaoru, T. (2007). Data Envelopment Analysis, 2end. Springer Science + Business Media, 22. https://doi.org/10.1007/1-4020-7798-x_1

Cooper, W. W., Seiford, L. M., \& Tone, K. (2006). Introduction to data envelopment analysis and its uses: With DEA-solver software and references. Springer Science \& Business Media. https://doi.org/10.1007/0-387-29122-9_4

Cooper, W. W., Seiford, L. M., \& Zhu, J. (2011). Data envelopment analysis: History, models, and interpretations. In Handbook on data envelopment analysis (pp. 1-39). https://doi.org/10.1007/978-1-4419-6151-8_1

Farrell, M. J. (1957). The measurement of productive efficiency. Journal of the Royal Statistical Society. Series A (General), 120(3), 253-290. https://doi.org/10.2307/2343100

Finkler, M. D., \& Wirtschafter, D. D. (1993). Cost-effectiveness and data envelopment analysis. Health Care Management Review, 18(3), 81-88. https://doi.org/10.1097/00004010-199301830-00010

Greene, W. (2004). Distinguishing between heterogeneity and inefficiency: Stochastic frontier analysis of the World Health Organization's panel data on national health care systems. Health Economics, 13(10), 959-980. https://doi.org/10.1002/hec.938 
Hamid, A. B. A., Lukman, H. I., Choy, C. S., \& Lin, B. (2009). Measuring supply chain performance among public hospital laboratories. International Journal of Productivity and Performance Management, 59(1), 75-97. https://doi.org/10.1108/17410401011006121

Hollingsworth, B. (2008). The measurement of efficiency and productivity of health care delivery. Health Economics, 17(10), 1107-1128. https://doi.org/10.1002/hec.1391

Hussein, M. A., Abdul, H., \& Mazhar, K. (.2011). Measuring of the Performance Efficiency of Educational Institutions by Using Data Envelopment Analysis. Takreet Journal of Administrative and Economic Sciences, 34(28).

Iswanto, A. H. (2015). Hospital Efficiency and Data Envelopment Analysis (DEA): An Empirical Analysis of Kemang Medical Care (KMC). Available at SSRN 2629898. http://dx.doi.org/10.2139/ssrn.2629898

Joe, Z. (2003). Quantitative Models for Performance Evaluation and Benchmarking: Data envelopment analysis with spreadsheets and DEA Excel solver. Kluwer Academic Publishers Group, Norwell, Massachusetts 02061 USA.

Kim, Y., \& Kang, M. (2014). The Measurement of Health Care System Efficiency: Cross-country Comparison by Geographical Region. Korean Journal of Policy Studies, 29(1), 21-44. https://doi.org/10.4040/jkan.2014.44.1.21

Kontodimopoulos, N., \& Niakas, D. (2005). Efficiency measurement of hemodialysis units in Greece with data envelopment analysis. Health Policy, 71(2), 195-204. http://dx.doi.org/10.1016/j.healthpol.2004.08.004

Lewin, A. Y., \& Morey, R. C. (1981). Measuring the relative efficiency and output potential of public sector organizations: An application of data envelopment analysis. Int. J. Policy Anal. Inf. Syst.;(United States), $5(4)$.

Lynch, J. R., \& Ozcan, Y. A. (1994). Hospital closure: An efficiency analysis. Journal of Healthcare Management, 39(2), 205.

Manzoni, A. I. (2009). Performance Measurement in Corporate Governance, Physica-Verlag Heidelberg, p. 98.

Ministry of Health in Saudi Arabia. (1435). Annual Health Statistical Book. Published by the Ministry of Health in Saudi Arabia in 1435 H, 1427.

Nadir, N. et al. (2013). Measurement of the efficiency of Container' Terminals Via Using Data Envelopment Analysis. Syria Journal of Tashreen University for Research and Sscientific Studies, a Series of Economic and Legal Science analysis, 35(8).

Nayar, P., \& Ozcan, Y. A. (2008). Data envelopment analysis comparison of hospital efficiency and quality. Journal of Medical Systems, 32(3), 193-199. https://doi.org/10.1007/s10916-007-9122-8

Rebba, V., \& Rizzi, D. (2006). Measuring Hospital Efficiency through Data Envelopment Analysis when Policy-Makers' Preferences Matter: An Application to a Sample of Italian NHS Hospitals. University Ca'Foscari of Venice, Dept. of Economics Research Paper Series, (13/06). https://doi.org/10.2139/ssrn.946885

Retzlaff-Roberts, D., Chang, C. F., \& Rubin, R. M. (2004). Technical efficiency in the use of health care resources: A comparison of OECD countries. Health Policy, 69(1), 55-72. https://doi.org/10.1016/j.healthpol.2003.12.002

Sahin, M., \& Bulent, S. (2011). Analyzing the Efficiencies of Hospitals: An Data Envelopment Analysis. Journal of Global Strategic Management, (10). https://doi.org/10.20460/JGSM.2011515804

Sarkis, J., \& Talluri, S. (2002). Efficiency measurement of hospitals: Issues and extensions. International

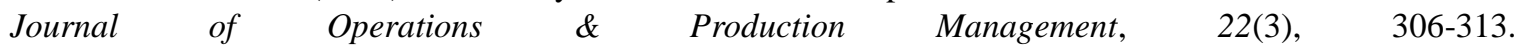
https://doi.org/10.1108/01443570210417605

Sherman, H. (1984). Hospital Efficiency Measurement and Evaluation, Empirical Test of aNew Technique. Medical Care, 22(10), 922-939. https://doi.org/10.1097/00005650-198410000-00005

Sherman, H. D., \& Zhu, J. (2006). Service productivity management: Improving service performance using data envelopment analysis (DEA). Springer Science \& Business Media.

Spinks, J., \& Hollingsworth, B. (2009). Cross-country comparisons of technical efficiency of health production: A demonstration of pitfalls. Applied Economics, 41(4), 417-427. https://doi.org/10.1080/00036840701604354 
Szczepura, A., Davies, C., Fletcher, J., \& Boussofiane, A. (1993). Efficiency and effectiveness in general practice. Journal of Management in Medicine. https://doi.org/10.1108/eb060565

\section{Copyrights}

Copyright for this article is retained by the author(s), with first publication rights granted to the journal.

This is an open-access article distributed under the terms and conditions of the Creative Commons Attribution license (http://creativecommons.org/licenses/by/4.0/). 